
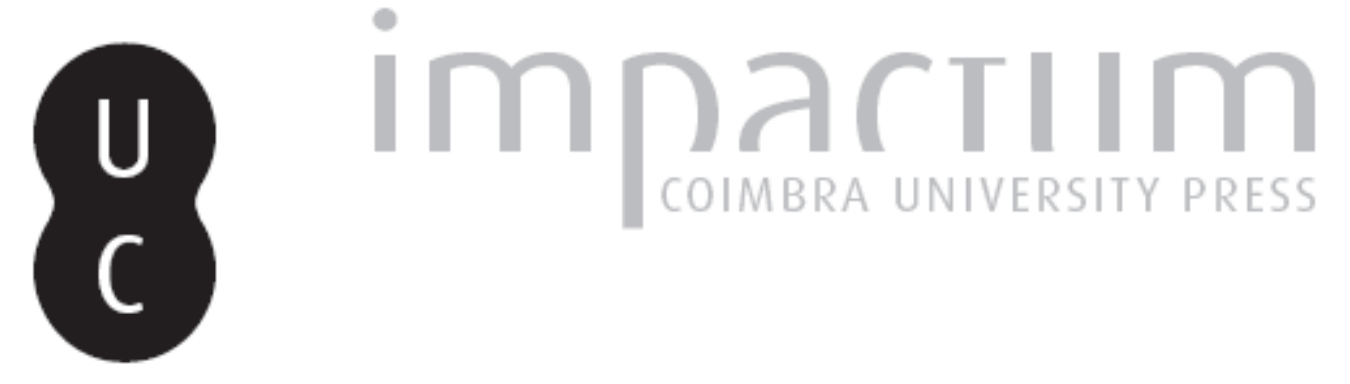

\title{
O confronto de Heidegger com o "motivo matemático" da metafísica moderna
}

\author{
Autor(es): $\quad$ Veiga, Itamar Soares
}
Publicado por: Universidade Católica de Petrópolis; Instituto Brasileiro de Informação em Ciência e Tecnologia

URL

persistente:

URI:http://hdl.handle.net/10316.2/33037

DOI:

DOI:http://dx.doi.org/10.14195/1984-6754_3-2_3

Accessed : $\quad$ 26-Apr-2023 09:34:56

A navegação consulta e descarregamento dos títulos inseridos nas Bibliotecas Digitais UC Digitalis, UC Pombalina e UC Impactum, pressupõem a aceitação plena e sem reservas dos Termos e Condições de Uso destas Bibliotecas Digitais, disponíveis em https://digitalis.uc.pt/pt-pt/termos.

Conforme exposto nos referidos Termos e Condições de Uso, o descarregamento de títulos de acesso restrito requer uma licença válida de autorização devendo o utilizador aceder ao(s) documento(s) a partir de um endereço de IP da instituição detentora da supramencionada licença.

Ao utilizador é apenas permitido o descarregamento para uso pessoal, pelo que o emprego do(s) título(s) descarregado(s) para outro fim, designadamente comercial, carece de autorização do respetivo autor ou editor da obra.

Na medida em que todas as obras da UC Digitalis se encontram protegidas pelo Código do Direito de Autor e Direitos Conexos e demais legislação aplicável, toda a cópia, parcial ou total, deste documento, nos casos em que é legalmente admitida, deverá conter ou fazer-se acompanhar por este aviso.

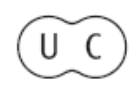



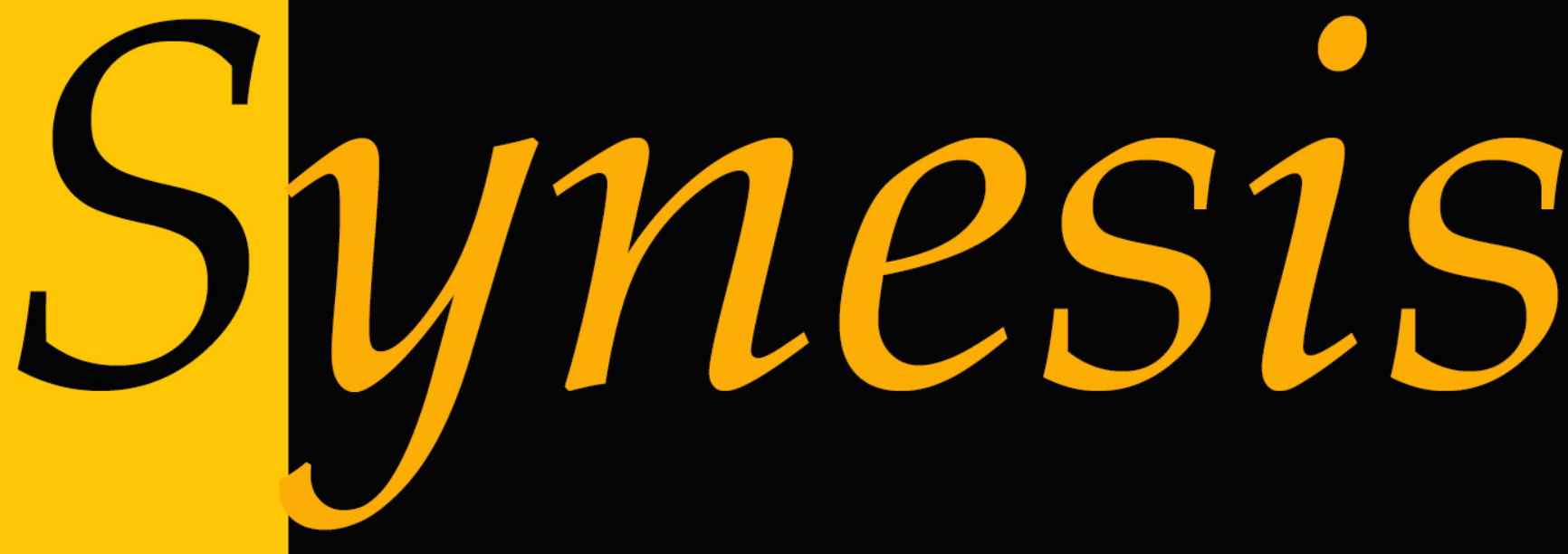

Revista do Centro de Teologia e Humanidades ISSN 1984-6754

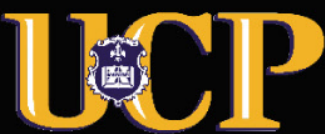




\title{
O CONFRONTO DE HEIDEGGER COM O "MOTIVO
}

\section{MATEMÁTICO” DA METAFÍSICA MODERNA ${ }^{1}$}

\author{
Itamar Soares Veiga ${ }^{2}$
}

Resumo: Esta investigação trata das relaçôes entre Heidegger e o conjunto da filosofia ocidental. Este conjunto é referido como metafísico, onde predomina atualmente a influência da metafísica moderna. A análise da metafísica moderna assume como ponto principal a ciência moderna, onde se destaca a física matemática. E, a análise da física matemática conduz para um aprofundamento do significado de "matemático" desde a Antiguidade grega. Heidegger projeta esta via de análise até a modernidade e esta investigação visa acompanhá-lo com o objetivo de destacar o caráter antecipatório do matemático. O modo de realizar este objetivo é através da seleção de alguns cursos de Heidegger em um período de 1928 até 1938. O resultado indica que há uma continuidade subjacente na filosofia de Heidegger, a despeito de uma divisão de fases e, também, destaca a importância do caráter antecipatório no elemento "matemático".

Palavras-chave: Ciência; Galileu; Matemático; Ente.

Abstract: This inquiry deals with the relationship between Heidegger and the whole of Western philosophy. This set is referred to as metaphysical, which one is currently dominated by the influence of modern metaphysics. The analysis assumes modern metaphysics as the focal point for modern science, which includes mathematical physics. Further, the analysis of mathematical physics leads to a deepening of the meaning of "mathematical" since Greek antiquity. Heidegger projects this way of analysis out to modernity and this inquiry aims at following him in order to highlight the anticipatory nature of the mathematician. In order to accomplishing this goal we've chosen to select some of Heidegger lectures from 1928 to 1938. The result indicates that there is an underlying continuity in Heidegger's philosophy, despite of a division of phases; it also highlights the importance of the anticipatory character of the "mathematical" element.

Keywords: Science; Galileo; Mathematical; Being.

\footnotetext{
${ }^{1}$ Artigo recebido em 15/10/2011 e aprovado para publicação pelo Conselho Editorial em 23/12/2011.

${ }^{2}$ Doutor em Filosofia pela Pontifícia Universidade Católica do Rio Grande do Sul. Atualmente é professor da Universidade de Caxias do Sul. Currículo Lattes: http://lattes.cnpq.br/4595214343309480. Email: inpesquisa@yahoo.com.br.
} 


\section{Introduçáo}

Heidegger é um filósofo que apresenta diferentes fases, mas há também uma continuidade subjacente. Um exemplo de diferenciação entre estas fases é alcançado através do próprio Heidegger, quando na Carta sobre o humanismo de 1946 ele afirma ter ocorrido uma mudança em sua filosofia nos anos de 1929/30. Em suas diferentes formas de apresentar sua continuidade filosófica, Heidegger realiza um confronto com a produção filosófica da história ocidental. Na sua auto-referida divisão entre duas fases (antes e depois da conferência $O$ que é metafisica? de 1929, GA-93), Heidegger trabalha o seu confronto na primeira fase através da violência hermenêutica da interpretaçáo dos demais filósofos e, de modo destacado, através do que ele denomina Destruktion ( $\$ 6$ de Ser e tempo $o^{4}$, GA-2).

A Destruktion é uma forma de ater-se ao positivo da tradição filosófica, procurando explorar os seus limites. No caso, não há uma negação ou uma refutação da tradição, mas sim um acolhimento que se une a uma interpretação específica. Esta interpretaçáo possui um ponto de partida também específico que é a temporalidade, ou conforme a própria analítica existencial, a historicidade do ser-aí (Dasein), que coloca frente à tradição a pergunta pelo fenômeno do tempo.

A outra forma de confronto após 1929 é a elaboração de uma história da essência da verdade do ser. Mais uma vez, neste caso, não há uma negação ou refutação da tradição filosófica, mas sim um escutá-la em seus diferentes sentidos epocais. Cada sentido epocal significa uma essência do ser que vigora. E, a partir da verdade da essência do ser, alcança-se a compreensão da verdade dos entes, separando uma época de outra. A interpretação se modifica em relação a Ser e tempo, e o ponto de partida não é mais o ser-aí, mas o ser e a história ${ }^{5}$ de

3 A referência entre parentes: (GA..) vai sempre ser complementada por um número que indica o volume da obras completas de Heidegger - Gesammtausgabe - editada por Vittorio Klostermann. Nas referências bibliográficas, onde estão as traduções em português, também inserimos esta respectiva numeração.

4 A obra Sein und Zeit de 1927, e publicada na GA em 1977, será referida com título em português ao longo do texto.

5 Gadamer ilustra este ponto da virada (Kehre) na filosofia de Heidegger: “[...] na virada parte-se do ser, ao invés de se partir da consciência quer pensa o ser ou do ser-aí [...]” (1987, p.191). 
diferentes sentidos alcançados ao longo do percurso da filosofia ocidental.

O estudo destes dois confrontos mostra que a continuidade filosófica que perpassa a filosofia de Heidegger repousa nas relaçóes entre ser e ente. Heidegger dedica-se a aplicar as consequências de cada um dos dois modos de interpretação. Em Ser e tempo (p.12-20, $\$ \$ 3$ e 4) onde predominou uma análise do ente ser-aí, temos o primado ôntico do ontológico deste ente frente à tarefa da pergunta pelo sentido do ser. E o modo como este ente, que é o homem, se apresenta frente a tradição é a finitude em seu caráter ontológico de ser-para-a-morte (Ser e tempo, $\$ 50)$. Esta finitude inscreve ontologicamente o tempo existencial na visualização do percurso milenar da filosofia ocidental. A contrapartida da virada (Kehre) de 1929, na conferência $O$ que é a metafísica? (mas também nas conferências Sobre a essência da verdade e $A$ essência do fundamento ambas no volume 9 das obras completas, GA-9) mostra que a relaçáo entre ente e ser se modifica. Heidegger se afasta da centralidade no ser-aí e se volta para a essência do ser que vigora e, assim vigorando, abre uma clareira (Lichtung) onde os demais entes são. Neste caso, é necessário se perguntar pelo sentido desta essência que vigora. E este perguntar conduz Heidegger a um confronto com a tradição filosófica através das palavras mais próximas aos demais filósofos: metafísica, fundamento, res cogitans, res extensa etc.

Este artigo visa se deter no segundo confronto estabelecido por Heidegger após os anos de 1929/30. E as obras que utilizaremos para analisar o "matemático" neste contexto conceitual são: Introdução à filosofia (GA-27, 1928/29), Ser e verdade (GA-36/37, 1933/34), O que é uma coisa? (GA-41, 1935/36) e a conferência A época da imagem de mundo (GA-5, 1938). Uma longa exposição sobre a matemática e a filosofia de Heidegger foi realizada por Oliver Souan $(2006)^{6}$, mas aqui vamos nos deter apenas no caráter de antecipaçáa do motivo matemático. O objetivo é, primeiramente, explicitar a compreensão de Heidegger sobre o fenômeno da ciência e, finalmente, propor uma interpretação desse caráter "antecipatório" existente no "motivo matemático" (Ser e verdade, p. 79 e seguintes). Esta interpretação procura fornecer subsídios teóricos para um reposicionamento do conceito de "matemático" para um

6 Diferentemente de Souan (2006, p.361-416) e também de Elden (2006) vamos aprofundar a relação do caráter antecipatório do matemático nos efeitos que a virada (Kehre) provocou na análise sobre o fenômeno da ciência e, nisto, na análise da concepção de "natureza" que permeou a metafísica moderna. A análise de Souan aprofunda os elementos gregos e aristotélicos da interpretação de Heidegger, neste sentido ele é acompanhado por Stuart Elden que, além disso, acrescenta um caráter sócio-político. 
âmbito não derivado. A obra Ser e verdade (GA-36/37) será utilizada como um eixo geral da análise.

\section{A Ciência Moderna e Galileu}

No segundo confronto de Heidegger com a tradição filosófica, ou seja, após a virada de 1929 (Kehre), é importante destacar uma divisão entre o "motivo matemático" e a constituição onto-teo-lógica da metafísica. Esta denominação de "constituição onto-teo-lógica" busca significar um contexto de influência da religiáo cristã sobre a produçáo filosófica ocidental. Em Ser e verdade, na parte referente ao curso "A questáo fundamental da filosofia" (curso do verão de 1933), Heidegger afirma que o significado de metafísica se altera em relação à incorporação do divino:

[...]. Para a maneira de pensar cristâ, porém, os seres da natureza, os seres naturais, são no fundo, criaturas, isto é, seres criados por Deus. O que está além da natureza é o divino, Deus. Este ser não está apenas fora dos limites da natureza, mas também, em sua essência e importância, está acima e é superior, é trans. A consideração de conteúdo já mostra uma interpretação especificamente cristá.

A partir desta compreensão do conceito não-natureza, no sentido de sobrenatureza divina, a palavra meta-física adquire uma outra significação; $\mu \varepsilon \tau \alpha$ já não remete para uma referência técnica na sequência dos escritos: post, e sim para um conteúdo determinado, entendido cristianamente ${ }^{7}$ dos respectivos escritos: trans, além da natureza. A natureza é acessível pelos sentidos em contraste com o supra-sensível. A metafísica, ao contrário, é o conhecimento das coisas divinas, do supra-sensível. O título de uma perplexidade torna-se, entáo, o nome para a espécie mais elevada possível do conhecimento humano. (HEIDEGGER, 2007, p.37).

Esta constituição onto-teo-lógica é analisada de forma mais detida por Heidegger em $\left(1956 / 57^{8}\right)$. Aqui ela é denominada como "motivo teológico-cristáo" e perfaz uma das partes que compóe a metafísica da filosofia. No movimento interpretativo que parte da história do ser

7 Optou-se pela escrita "cristianamente" do que "cristãmente" que consta na tradução em língua portuguesa. Em princípio, pensa-se que não há uma alteraçáo significativa no sentido da frase, pois a palavra continua tendo uma função adverbial.

8 Trata-se do curso de inverno sobre a Ciência da lógica de Hegel. Este escrito não será analisado, pois se afasta do âmbito selecionado dos anos de 1928 até 1938, previamente delimitado. 
para a verdade dos entes, Heidegger afirma que: "Os dois motivos principais de determinação para a constituição da metafísica ocidental são: 1. o matemático e 2. o teológico-cristão (já caracterizado)." E complementa: “Tudo, porém, com o propósito básico de esclarecer e orientar nossa própria presença histórica." (HEIDEGGER, 2007, p.44). Nas páginas anteriores, como referido mais acima, Heidegger abordou o "motivo teológico-cristáo". É necessário agora abordar o "motivo matemático", objeto principal deste artigo.

No ano de 1928, no semestre de inverno (portanto 1928-1929), Heidegger ministrou um curso que incluía alunos de outras áreas de conhecimento que não a filosofia. Este curso foi dividido entre duas grandes seçôes: filosofia e ciência e filosofia e visão de mundo. $\mathrm{Na}$ primeira seção sobre a ciência já se encontram elementos da sua virada filosófica, ou seja, da modificação do vetor de análise para a história do ser. Pois uma análise da ciência como um todo em sua presença na cultura intelectual do ocidente implica necessariamente uma consideração sobre a verdade do ente, mesmo quando a verdade é algo aceito cientificamente. E a verdade do ente somente é alcançada pelo ser e por sua essência que vigora conforme um determinado sentido. É este sentido, na forma de um sentido epocal, que Heidegger visa abranger ao tratar da ciência.

O curso de 1928/29 coloca em discussão a ideia de explicitar a metafísica ocidental através de seus diferentes sistemas filosóficos, assumindo como foco específico o "elemento" matemático. O matemático se torna um fio condutor importante para os filósofos modernos, mas a sua exposição e utilização "explícitas" ocorrem com Galileu durante o desenvolvimento da física matemática. Heidegger trabalha a ideia do matemático a partir da sua origem grega em uma abordagem etimológica. Mas o objetivo de Heidegger é mostrar a modificação realizada por Galileu frente ao mundo antigo e medieval. Esta modificaçáo implicou uma mudança no modo moderno de compreensão do ser (transformado em "natureza") e dos entes (transformados em corpúsculos físicos definidos espaço-temporalmente). Portanto, a compreensão que Galileu imprime à matemática é uma alteração daquilo provém desde a antiguidade, e que se encontrava já em uma constituição original. Galileu modifica a constituição original, gerando uma outra "constituiçáa” determinante, e esta determina todo o conhecimento científico posterior. Que isso seja uma modificação da relação entre ser e ente é 
algo que será demonstrado por Heidegger.

Galileu desempenha um papel importante no modo de ser moderno. Heidegger apresenta este aspecto no curso de 1928/29 com as seguintes palavras:

A intelecção epocal de Galileu foi reconhecer que, caso eu queira, por meio do experimento, interrogar a natureza quanto ao que ela é e como ela é, já é preciso ter antes de tudo, um conceito do que compreendo por "natureza": que uma delimitaçáo do que é compreendido por natureza precisa anteceder a toda investigaçáo dos fatos, todo experimento. No entanto, Galileu não formulou essa pergunta de maneira puramente platônica. Ao contrário, ele fixou um conceito de natureza segundo o qual a natureza é tomada como uma conexão de corpos móveis, de entes cujo caráter fundamental reside na extensão espacial e temporal, sendo que o movimento náo é outra coisa senáo alteração de lugar no tempo. Por meio dessa determinação fundamental da natureza, a multiplicidade do ente é imediatamente homogeneizada, isto é, ela assume um mesmo modo de ser no sentido de que a natureza é determinada de uma maneira uniforme em termos quantitativo-matemáticos tanto em relação ao seu caráter espacial quanto em relação ao seu caráter temporal. (HEIDEGGER, 2008, p.201).

A interpretação do processo intelectual desenvolvido por Galileu é realizada através de uma relação entre ser e ente. Esta relação não é explícita de imediato, mas ela é percebida com facilidade em algumas expressôes da citação acima. Assim, por exemplo, na expressão: "Por meio dessa determinação fundamental da natureza” temos o significado do ser enquanto "natureza" e, com a expressão complementar: "a multiplicidade do ente é imediatamente homogeneizada", temos o âmbito ôntico; portanto, temos como vetor de análise sobre o desempenho de Galileu, a relaçáo ser e ente.

Esta é uma das formas de abordagem da época moderna. Trata-se de uma interpretação que será orientada pelo papel da matemática em consonância com uma recuperação do significado grego da palavra $\mu \alpha \theta \eta \mu \alpha \tau \alpha$. Contudo, isto somente se tornará mais claro com uma análise de outras interpretaçóes mais acessíveis e comuns para definir em que a época moderna se difere das duas épocas anteriores: a antiga e a medieval. Heidegger descarta que a época moderna tenha: 1- se detido nos fatos e as anteriores não; 2- tenha trabalhado com o experimento e as anteriores não; 3- fez uso da matemática, mas isso não é toda explicação, mas parte dela. Vejamos a passagem na qual se encontram estas três observaçôes: 
A física moderna é denominada física matemática, e o fato de ela proceder indutivamente é visto como um traço particular ante à física medieval. A física moderna observa os fatos tal como eles são, enquanto a especulação medieval buscava obter para si um conhecimento da natureza a partir de meros conceitos genéricos. Náo obstante, tanto na Antiguidade quanto na Idade Média, já havia uma ciência natural que observava os fatos. Dessa forma, o caráter indutivo não toca a essência da física moderna. Indo além, costuma-se dizer que, em contraposiçáo à antiga ciência natural, a moderna ciência natural trabalha com o experimento. Enquanto a antiga ciência natural dependia de observaçôes contingentes, no interior do experimento a natureza é em certa maneira obrigada a responder a determinadas perguntas. Mas sabemos que antiga ciência natural também já trabalhava com os experimentos e, contudo, não tinha o caráter alcançado pela física por meio de Galileu. Em terceiro lugar, a diferença parece consistir no fato de a física atual ser matemática, enquanto o conhecimento medieval da natureza não podia fazer um tal uso, porque o desenvolvimento da matemática moderna acontece juntamente com o surgimento da física matemática. (HEIDEGGER, 2008, p.199-200).

Nesta longa passagem temos os três estágios que buscam definir a ciência moderna a partir da Física. Esta crítica também aparece nos escritos posteriores à 1928/29. No curso de inverno de 1933/34, publicado no volume Ser e verdade das obras completas, Heidegger diz que é um erro pensar que a ciência moderna se distingue da antiga por causa da introdução do experimento ou da matematização $(2007$, p.171). O filósofo afirma que a matematização é mais do que a passagem de uma análise qualitativa para uma análise quantitativa. A matematizaçáo implica, com Galileu, uma nova forma de ver e organizar o ente, portanto, uma nova concepçáo da essência da verdade do ser.

No curso de inverno 1935/36: O que é uma coisa? (Die Frage nach dem Ding - Zu Kants Lehre von transzendentalen Grundsätzen, GA-41), o filósofo explica de forma detalhada estas caracterizaçóes diferenciadoras divididas nos três aspectos: fato, experimento e matemática; e estende sua interrogação para um aprofundamento da necessidade de esclarecer o que seja - isto - o matemático:

Com as três referidas caracterizaçóes da ciência moderna: ciência de fatos, ser experimental e ciência que mede - não encontramos o traço fundamental da nova posiçáo do saber. $\mathrm{O}$ traço fundamental deve residir naquilo que, fornecendo-lhe a medida, determina completamente, de um modo igualmente originário, o movimento-de-fundo da ciência enquanto tal: tratase da relação-de-trabalho com as coisas e do projeto metafísico da coisialidade da coisa. De que modo devemos conceber este traço fundamental? 
Atribuímos um nome ao caráter-de-fundo, que procuramos, da moderna atitude do saber, ao dizermos que a nova pretensão do saber é matemática. [...].

A pergunta decisiva é esta: que significa aqui "matemática" e "matemático"? (HEIDEGGER, 1992, p.74-75).

Nesta seção, viu-se que a Galileu é um dos protagonistas indispensáveis para a compreensão da época moderna e que a forma imediata de compreender a física moderna ou a ciência moderna, através de considerações usuais sobre a visão de fatos, o experimento e a matematizaçáo, pode resultar em um não descobrimento da essência desta própria época. $\mathrm{O}$ principal fator da mudança ocorrida no conhecimento filosófico e da natureza remete à matemática. O próximo passo será tratar do matemático, acompanhando as interpretações de Heidegger sobre mudanças causadas pela ciência moderna na forma como concebemos os entes e, por isso, o ser.

\section{O "Matemático" em sentido moderno e em seu sentido original}

Heidegger vai estudar a matematizaçáo na ciência através com um aprofundamento sobre a matemática. Este aprofundamento será orientado pelo adjetivo "matemático", ao qual se aplicam diferentes formas de tratamento do ente. No caso da época moderna, o tratamento matemático do ente está determinado pela forma como se concebe a efetivaçáo do ente e a sua totalidade. A totalidade do ente na época moderna é compreendida através da expressão "natureza". E a forma da efetivação do ente, ou seja, o modo em que o ente é "descoberto" pela ciência moderna é através de relaçôes quantitativas (a medição e o cálculo, os quais dependem de uma prévia disposição espaço-temporal do ente) e da causa e efeito.

Contudo, o "matemático" não vai apenas ser uma consequência da aplicação de cálculo sobre os eventos de causa e efeito na natureza. O "matemático" abrange um espectro de consequências que ultrapassam as determinaçóes sobre os entes em apenas um âmbito. Este é o caso da determinaçáo através da natureza (âmbito) sobre os entes (objetos da experiência). As consequências da compreensão do "matemático", por parte de Heidegger, ultrapassam a iniciativa moderna iniciada com Galileu e recuperam os significados encobertos da origem da 
palavra na Antiguidade grega, o $\mu \alpha \theta \eta \mu \alpha \tau \alpha$.

Primeiramente, o autor nos afasta de uma compreensão usual sobre o que significa o matemático vinculado à ciência moderna. No curso de 1928/29, ele afirma:

Em primeira linha, o termo "matemático" não significa aqui o fato de a matemática calcular e obter resultados numericamente exatos; isso é apenas uma consequência. Matemática é um caminho e um meio de tomar a natureza assim estabelecida, de expressar o ser da natureza. Essa é estabelecida como determinada e determinável por meio de quantidades. Quantum - extensio, espaço, tempo, movimento, força. A física moderna é matemática porque o a priori está, de certa maneira, determinado. Todo experimento (juntamente com os instrumentos de medição aí utilizados) é estabelecido e interpretado sob a luz de uma determinação prévia do ser do ente. (HEIDEGGER, 2008, p.200).

Esta relaçáo moderna com o ente no sentido de medi-lo e com isso quantificá-lo, implica uma concepção de "evento natural" (2008, p.202) prévia e totalizada sobre o ente a ser medido. Heidegger ilustra muito bem este aspecto, ao explicar o que significa "mediçáa":

Medição significa constatação de coincidências. Tomemos, por exemplo, o relógio. Olhamos diariamente para o relógio e constatamos a hora. Será que a confluência, a coincidência da posiçáo de um ponteirinho com um determinado traço na superfície do relógio deve significar uma mediçáo do tempo? Essa mediçáo do tempo se nos tornou tão óbvia que náo notamos mais absolutamente o mundo de pressupostos que reside aí quando olhamos para o relógio. Essa utilização do relógio só é uma medição do tempo se tomo essa coisa como relógio, isto é, se a utilização é orientada pela medição do tempo, pelo sol. Assim, só se está em condiçóes de utilizar um instrumento que serve para a medição se uma compreensão da natureza se encontra à base de uma tal utilização. (HEIDEGGER, 2008, p.202).

Heidegger modifica a direção da resposta para a pergunta sobre o que significa "matemático" para uma resposta etimológica sobre o que significa a palavra em sua origem grega. Com isso, ele quer evitar que a compreensão esteja sempre já subsumida ao modo como compreendemos a ciência moderna. A mudança ocorre nos três principais registros bibliográficos, os quais reportam a mesma posiçáo sobre o matemático, mas expressada com outras palavras: o curso de 1928/29 (Introdução à metafísica), o curso de 1933/34 (Ser e verdade) e o curso de 1934/35 (O que é a coisa?). No texto do meio, Ser e verdade, ele afirma:

Que significa, agora, em oposição a tudo isso, $\tau \alpha \mu \alpha \theta \eta \mu \alpha \tau \alpha$ ? Se respondermos: o "matemático", corremos o risco de uma má interpretação 
do conceito grego. Pois com "matemático", pensamos logo e exclusivamente em número e relaçóes numéricas, em ponto, linha, superfície, corpos (elementos, figuras do espaço). Todavia, tudo isso só se chama de matemático num sentido derivado, à medida que satisfaz justamente ao que pertence originária e propriamente a essência dos $\mu \alpha \theta \eta \mu \alpha \tau \alpha$, $\mu \alpha \theta \eta \mu \alpha \tau \alpha$ não são para se esclarecer pelo matemático, mas ao contrário.

E o que pertence originalmente à essência dos $\mu \alpha \theta \eta \mu \alpha \tau \alpha$ ? Ensinar o que é para ser ensinado, o que se pode aprender e ensinar. (HEIDEGGER, 2007, p.46).

O "matemático", em sua origem grega, possui uma relação com o deixar ser do ente, para que assim ele possa ser aprendido na forma de uma liçáo. Mas o apreender, mediante uma lição ou o tomar conhecimento de algo, depende de uma conformaçáo prévia daquilo que se vai conhecer. O matemático é precisamente esta disposição prévia de poder ser apreendido. $\mathrm{Na}$ recuperaçáo do sentido da palavra grega persiste a noçáo de que o que se conhece com o matemático é, precisamente, aquilo que já se conhecia antes. No curso de 1934/35, Heidegger diz:

$\mathrm{Na}$ verdade, este "tomar conhecimento" é a essência autêntica do conhecer, $\mu \alpha \theta \eta v \sigma ı$ c. As $\mu \alpha \theta \eta \mu \alpha \tau \alpha$ são as coisas na medida em que as tomamos no conhecimento, enquanto tomamos conhecimento delas, como aquilo que verdadeiramente, já sabemos de modo antecipado: o corpo como corporidade; na planta, a vegetabilidade, no animal, a animalidade, na coisa, a coisalidade, etc. Este verdadeiro aprender é, por consequência, um tomar muito peculiar, um tomar no qual aquele que toma, toma, no fundo, aquilo que já tem. A este aprender corresponde, também, o ensinar. Ensinar é um dar, um oferecer; no ensinar, não é oferecido o ensinável, mas é dada somente ao aluno a indicaçáo de ele próprio tomar aquilo que já tem. (HEIDEGGER,1992, p.79).

Este conhecimento que "já sabemos de modo antecipado" revela o caráter de antecipaçáo que existe no "matemático". Este caráter de antecipaçáo vai ao encontro do caráter antepredicativo da existência humana diante das sentenças declarativas com valor de verdade. Pode-se acrescentar também que este caráter antecipatório desloca a determinação de verdade do ente para duas direçóes possíveis: em primeiro lugar, para o âmbito da vigência da verdade da essência do ser. Como foi anunciado por Heidegger na Carta sobre o humanismo: "Aqui o todo se inverte" (HEIDEGGER, 1983, p.156), ou seja, há uma virada filosófica, onde a essência do ente depende da verdade da essência do ser: “[...] para que na luz do ser, o ente se 
manifeste como ente que efetivamente é.” (Idem, p.158). E este é exatamente o caso da física moderna que, ao construir suas proposiçóes verdadeiras sobre os entes ou sobre os "eventos naturais", desenvolveu desde já uma interpretação que dependia de uma determinação maior, ou seja, uma determinaçáo de como era a natureza.

Em segundo lugar, o caráter antecipatório do "matemático" se desloca para o âmbito da existência humana na medida em que o homem é um ente que compreende os demais entes (conforme a analítica existencial desenvolvida em Ser e tempo). Esta vinculação entre o matemático e a existência humana pode ser mostrada através de duas passagens. Na primeira Heidegger refere-se ao "matemático" como um elemento que já possuímos, pois o "matemático" traduz uma rede de sentido que remete a um "acerca" das coisas. E, assim, o "matemático" entra em consonância com o sentido ontológico do "signo" exposto por Heidegger no $\$ 17$ de Ser e tempo. Este parágrafo, efeito da aplicação metodológica dos fenômenos enquanto indícios-formais, prepara o $\$ 18$ que apresenta a significatividade (Bedeutsamkeit) em Ser e tempo, a qual é fundamental para explicitação do existencial compreensão (\$ 31): "Na compreender do em-função-de [Worumwillen] está co-aberta, nele, a significatividade fundante [gründende Bedeutsamkeit].” (HEIDEGGER, 1977, p.190) . Já na obra de 1934/35, a dimensáo existencial pode ser vista nesta passagem: "O $\mu \alpha \theta \eta \mu \alpha \tau \alpha$, o matemático, é aquele 'acerca' das coisas que já conhecemos verdadeiramente, de modo antecipado, aquilo que, em consequência, não começamos por ir buscar às coisas, mas que, de certo modo, levamos conosco até elas. (HEIDEGGER, 1992, p.80).

Esta dimensão existencial é ampliada, quando Heidegger aborda a Academia de Platão, para exemplificar que a compreensão do "matemático" depende de um conhecimento de fundo, o qual se mostra como um conhecimento que já possuímos de antemão. Trata-se novamente de um trecho do curso de 1934/35:

Por isto, colocou Platão á entrada da sua Academia, a seguinte frase:

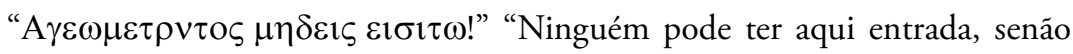
tiver compreendido o matemático". Esta frase não significa tanto, nem em

9 Podemos encontrar o caráter antecipatório no existencial compreensão em relação com o interpretar. Isto é desenvolvido no $\$ 32$ : “Toda simples visão antepredicativa [vorprädikative schlichte Sehen] do prontamente-àmão [Zuhandenen] é em si mesma compreensora-interpretante" (HEIDEGGER, 1977, p.198). O “caráter antecipatório" da compreensão do ser-aí está referido na expressão: "antepredicativa”. 
primeiro lugar que uma pessoa deve estar formada numa disciplina chamada "geometria", mas que compreende que as condiçóes-de-fundo para o podersaber adequado e para o saber são o saber dos pressupostos fundamentais de todo saber e da atitude suportada por um tal saber. Um tal saber que não estabelece o seu fundamento de acordo com a sua essência e que, ao fazê-lo, não se limita a si mesmo, não é um saber, mas apenas um opinar. $\mathrm{O}$ matemático, no sentido originário do aprender-a-conhecer aquilo que já se conhece, é o pressuposto fundamental do trabalho "acadêmico". (HEIDEGGER, 1992, p.82).

O sentido moderno do "matemático" se consolida como imagem de mundo, na qual se pode alcançar proposições verdadeiras ou falsas como as da física aplicada. E, assim, através do "matemático", seja por causa do seu sentido original, seja por causa da sua combinação crítica com o sentido moderno, gera-se um espaço de jogo, dentro do qual é possível analisar toda uma época.

Heidegger em sua conferência de 1938 A época da imagem de mundo (GA-5), vai considerar a ciência moderna como o fenômeno mais determinante dentre outros fenômenos da modernidade (os quais são: a técnica mecânica; a arte como objeto da vivência; a cultura enquanto cultivar a si e, por isso, política cultural; a desdivinização: a indecidibilidade sobre o Deus e os Deuses, transformando o tema em "vivência religiosa"). E sob, o fenômeno da ciência moderna, percorre o fio condutor do "matemático" em ambos os sentidos já referidos.

A modernidade é considerada como tomada pela tradição metafísica. O posicionamento de Heidegger frente a metafísica ocidental pode ser apreendido em sua busca pelo caráter mais determinante que vigora em cada época. Isto se encontra assim na conferência A época da imagem de mundo:

No âmbito da metafísica realiza-se a reflexáo sobre a essência do ente e uma decisão sobre a essência da verdade. A metafísica funda uma época à medida que ela lhe dá o fundamento da sua forma essencial por meio de uma determinada interpretaçáo do ente e uma específica concepçáo da verdade. Esse fundamento domina todos os fenômenos que distinguem a época. Inversamente, o fundamento metafísico deve revelar-se nesses fenômenos a uma reflexáo suficiente a seu respeito. Reflexão é a coragem de tornar as verdades das pressuposiçóes próprias e o espaço das metas próprias na questão mais digna de ser problematizada. (HEIDEGGER, 2005, p.192).

$\mathrm{Na}$ passagem acima Heidegger refere-se a reflexão como uma coragem de enfrentar as 
verdade contida nas pressuposiçóes. Uma destas pressuposiçóes é claramente o caráter ambíguo (original e moderno) do "matemático". E, uma vez que o fenômeno da ciência é determinante na análise da modernidade, esta pressuposição aumenta em importância. Antes mesmo de apresentar os demais fenômenos, Heidegger destaca "técnica mecânica e, o que é mais importante, a "matemática da natureza" que existe na origem da ciência moderna:

Aos fenômenos essenciais da modernidade pertence a sua ciência. Um fenômeno de igual importância é a técnica mecânica, porém não se pode interpretá-la falsamente como mera aplicação à práxis da moderna ciência matemática da natureza. A técnica mecânica é, ela mesma, uma transformação independente da práxis, de tal modo que esta primeiramente exige um emprego da ciência matemática da natureza. A técnica mecânica permanece até agora o rebento mais visível da essência da técnica moderna, que é idêntica à essência da metafísica moderna." (HEIDEGGER, 2005, p.191-192).

O que se nomeia como "técnica mecânica" exige desde já a "ciência matemática da natureza”. A forma moderna de interpretar a natureza, como um conjunto de relações causais entre os fenômenos orientou-se pelo uso de recursos matemáticos com Galileu. Em seu livro $O$ Ensaiador, Galileu é explícito ao ressaltar a importância da matemática:

A filosofia encontra-se escrita neste grande livro que continuamente se abre perante nossos olhos (isto é, o universo), que não se pode compreender antes de entender a língua e conhecer os caracteres com os quais está escrito. Ele está escrito em língua matemática, os caracteres são triângulos, circunferências e outras figuras geométricas, sem cujos meios é impossível entender humanamente as palavras, sem eles nós vagamos perdidos dentro de um obscuro labirinto. (GALILEI, 1996, p.46)

A física, como toda ciência, se coloca frente a realidade, na forma de delineamento de uma regiáo de objeto (a regiáo de objetos da natureza é um delineamento sobre os entes, portanto depende de uma relação entre ser e ente). A física analisa e busca as relaçóes dos seus "objetos de estudo" a partir de um âmbito previamente delineado. Na conferência $A$ época da imagem de mundo, Heidegger compreende esta relaçáo da física sobre o "real" como uma estipulação:

Física é em geral o conhecimento da natureza, particularmente, entáo, o conhecimento corpóreo material em seu movimento, pois esse corpóreo mostra-se imediatamente e sem exceçáo em todo o natural, mesmo que de 
maneira diferenciada. Quando, pois, a Física constitui-se expressamente em matemática, entáo isso significa: por intermédio dela e para ela algo é estipulado de uma maneira enfática como já conhecido de antemáo. Essa estipulação diz respeito a nada menos que o esboço daquilo que futuramente deve ser a natureza para o conhecimento investigador dela: a coesão de movimento, encerrada em si, de pontos de massa referidos espaçotemporalmente." (HEIDEGGER, 2005 p.195).

A estipulação depende de um campo prévio que é âmbito. Este âmbito prévio é entendido como algo que é referido "espaço-temporalmente" como os "pontos de massa". Isto se compreende na palavra "esboço" utilizada por Heidegger na expressão "esboço daquilo que futuramente deve ser". "Estipulação" e "esboço" recuperam significados do "matemático" já mencionados. Contudo, a conferência segue o seu próprio rumo, buscando esclarecer passo a passo como o fenômeno da ciência possui determinaçóes sobre o todo da modernidade.

Heidegger afirma que a essência da ciência atual é "a investigaçáo", a partir dessa consideração: "A essência do que se denomina hoje ciência é a investigação. Em que consiste a essência da investigaçáa? Consiste em que o conhecer se instala a si mesmo como um proceder num âmbito do ente, da natureza ou da História” (HEIDEGGER, 2005, p.194). Torna-se, então, necessário explicar o que significa "proceder":

Proceder não significa aqui apenas método, o procedimento, pois todo proceder já carece de um setor aberto em que se move. Mas precisamente o abrir de um tal setor é o procedimento fundamental da investigação. Ele se realiza pelo fato de que se projeta num âmbito do ente, por exemplo, na natureza, um determinado esboço dos processos naturais. O projeto traça previamente a maneira pela qual o proceder conhecedor deve ligar-se ao setor aberto. Essa ligação é o rigor da investigação. Pelo projeto do esboço e da determinação do rigor, o proceder assegura para si o seu setor de objetos em meio ao âmbito do ser. (HEIDEGGER, 2005, p.194).

O "proceder" exige, de forma distintiva, "um setor aberto". E Heidegger avança para uma explicação do procedimento através do projeto. Ambos, procedimento e projeto são duas inserçóes interpretativas sobre a essência da ciência. E, estas inserçóes interpretativas possuem como fundamento o fio condutor do "matemático", o qual remete a uma relaçáo de determinação do ser sobre o ente, no caso da época moderna, de uma determinação da natureza (ser) sobre um objeto de estudo (ente). 
Finalmente, a ciência se mostra como um fenômeno que se mostra especializado frente a diferentes setores de objetos. Esta especialização da ciência não é um mal, mas sim "a causa do progresso de toda pesquisa" (HEIDEGGER, 2005, p.200). Desta forma a ciência consegue desenvolver mais seu caráter de projeto e de investigação. Com este desenvolvimento a ciência moderna encontra-se com um processo fundamental: "a empresa" (HEIDEGGER, 2005, p.200). E, assim, o seu fenômeno se reflete em toda a modernidade.

\section{Consideraçóes Finais}

Apenas a interpretaçáo do fenômeno da ciência, na modernidade, percorre um caminho que se converte na necessidade de explicar este papel peculiar do "matemático". Contudo, esta explicaçáo da ciência vinculada à essência de uma instituiçáo moderna como a "empresa" sob a égide da ciência moderna e, por isso, mais fundamentalmente através do matemático, já encontrava uma sustentação teórica nos cursos de Heidegger desde o final dos anos 20. Esta sustentaçáo teórica se mostra ainda mais efetiva quando se discute apenas a ciência moderna e o modo como ela reduz e consolida a relaçáa entre ser e ente. Assim, uma forma de desfazer uma redução consolidada deste operar do pensamento científico moderno é através do aprofundamento do que significa "matemática" atualmente e, "matemático" no sentido grego originário.

A explicação de Heidegger do "matemático", a partir da origem grega da palavra, gera um âmbito importante que não é, por si só, redutor e voltado ao ente. Este âmbito revela o caráter de antecipaçáo existente no "matemático" e que se conjuga com outras posiçóes filosóficas do próprio Heidegger. Dentre estas posições, encontram-se a dimensão antepredicativa na linguagem, o uso dos indícios-formais (formale Anzeigen) e o caráter antecipatório do cuidado (em alemão die Sorge $\$ 41$, HEIDEGGER, 1977, p.254-261) que é um existencial do ser-aí. Todas estas posiçóes teóricas náo estão imediatamente vinculadas ao "matemático" e nem à ciência, mas não obstante, elas mostram uma relação entre ser e ente (e no caso da analítica existencial entre ente e ser) que revela a continuidade fundamental na filosofia de Heidegger. Resta ainda uma pergunta, que propomos a partir dessas reflexóes sobre o caráter antecipatório do "motivo matemático" em Heidegger. Ela representa uma posição do 
autor deste presente artigo e, se expressa assim: até quando a ambigüidade fundamental, entre o sentido original e o "sentido moderno" do "motivo matemático", poderá permanecer implícita no atual desenvolvimento científico-tecnológico? 


\section{Referências Bibliográficas}

ELDEN, S. Speaking against number - Heidegger, language and politics of calculation. Edinburgh: Edinburgh University Press, 2006.

GALILEU, G. O Ensaiador. São Paulo: Editora Nova Cultural, 1996, tradutora: Helda Barraco.

GADAMER, H-G. Neuere Philosophie - Hegel, Husserl, Heidegger. Tübigen: Mohr Siebeck, 1987, Gesammelte Werk, v.3.

HEIDEGGER, M. A época da Imagem de Mundo. IN: SCHNEIDER, P. R. O Outro Pensar. Ijuí: UNIJUÍ, 2005, tradutor: Paulo Schneider, p.191-232 (GA-5).

Conferências e escritos filosóficos. São Paulo: Abril Cultural, 1983, tradutor: Ernildo Stein, (GA-9).

- Introduçáo à filosofia. São Paulo: Martins Fontes, 2008, tradutor: Marco Antonio Casanova, (GA-27).

Que é uma coisa? - Doutrina de Kant dos Princípios Transcendentais. Lisboa: Ediçóes 70, 1992, tradutor: Carlos Morujáo, (GA-41).

Ser e Verdade. 1. A questáo fundamental da filosofia. 2. Da essência da verdade. Petrópolis: Vozes, Bragança Paulista: Editora Universitária São Francisco, 2007, tradutor: Emmanuel Carneiro Leão, (GA-36/47).

_. Sein und Zeit. Frankfurt am Main: Vittorio Klostermann, 1977. (GA-2).

SOUAN, O. Heidegger et lês mathématiques. IN: CARON, M. (org.) Les Cahiers d'Historie de la Philosophie. Paris: Les Editions du CERF, Paris, 2006, p.361-416. 